\title{
Health-related Quality of Life in Emphysema
}

\author{
Robert M. Kaplan' ${ }^{1}$ and Andrew L. Ries² \\ ${ }^{1}$ Department of Health Services, University of California, Los Angeles, Los Angeles, California; and ${ }^{2}$ Departments of Medicine and Family and \\ Preventive Medicine University of California, San Diego, San Diego, California
}

\begin{abstract}
Patients with emphysema may experience reduced health-related quality of life (HRQOL). HRQOL measures have evolved from two different measurement traditions: psychometric theory and decision theory. Psychometric methods typically create a profile of outcomes, whereas decision theory methods offer a summary score on a continuum ranging from $\mathbf{0 . 0}$ (for death or worst possible health) to $\mathbf{1 . 0}$ (for best possible health). Decision theory methods are better suited for cost-effectiveness studies. Generic HRQOL measures can be applied to any disease population, whereas disease-targeted measures are tailored to a specific clinical condition. Disease-targeted measures are typically more sensitive to clinical change, but cannot offer a comparison basis for different clinical conditions. This article reviews the measurement of HRQOL in patients with emphysema. The National Emphysema Treatment Trial (NETT) offers an example of the application of both generic and disease-targeted, as well as profile and decision theory, methods. The NETT illustrates how HRQOL measures can be used to assess outcomes and estimate cost-effectiveness in a major clinical trial.
\end{abstract}

Keywords: health-related quality of life; emphysema; outcomes assessment; quality-of-life measurement

Patients with emphysema experience significant limitations in daily activities and reduced quality of life. Evidence supports the value of medical management and pulmonary rehabilitation for emphysema. Despite important advances in medical management, the promise of medical therapy is limited. Lung volume reduction surgery (LVRS) offers the potential to enhance quality of life for selected patients who have completed pulmonary rehabilitation.

The goals of surgical and medical treatments for emphysema are to extend life expectancy and to improve quality of life. Medicines have side effects and surgery is associated with operative and perioperative risks. Recovery from surgery necessarily reduces quality of life and functioning in the short term. These effects are important, but often are difficult to quantify. Healthrelated quality of life (HRQOL) measures attempt to characterize the negative and positive effects of a disease as well as its effect on quality of life.

HRQOL measures have been developed over the past 30 years, and have been commonly used to study emphysema. A PubMed search cross-referencing chronic obstructive pulmonary disease (COPD) with quality of life (in June 2007) produced

(Received in original form June 27, 2007; accepted in final form September 12, 2007) The National Emphysema Treatment Trial (NETT) is supported by contracts with the National Heart, Lung, and Blood Institute (N01HR76101, N01HR76102, N01HR76103, N01HR76104, N01HR76105, N01HR76106, N01HR76107, N01HR76108, N01HR76109, N01HR76110, N01HR76111, N01HR76112, N01HR76113, N01HR76114, N01HR76115, N01HR76116, N01HR76118, and N01HR76119), the Centers for Medicare and Medicaid Services (CMS), and the Agency for Healthcare Research and Quality (AHRQ).

Correspondence and requests for reprints should be addressed to Robert M. Kaplan, Ph.D., Wasserman Professor, and Chair, Department of Health Services, University of California, 650 Charles E. Young Drive, Los Angeles, Los Angeles, CA 90095-1772. E-mail rmkaplan@ucla.edu

Proc Am Thorac Soc Vol 5. pp 561-566, 2008

DOI: $10.1513 /$ pats.200706-080ET

Internet address: www.atsjournals.org
1,704 references and the intersection of emphysema and quality of life yielded 313 references. The American Thoracic Society maintains a website that summarizes quality-of-life measures that can be used in outcomes research for lung disease (see www.atsqol.org). The site lists measures by disease and offers references on their use.

The purpose of this article is to review HRQOL measurement in emphysema studies with emphasis on measures chosen for the National Emphysema Treatment Trial (NETT). More comprehensive reviews of HRQOL in chronic lung disease are available elsewhere (1).

\section{DISTINCTIONS BETWEEN MEASURES OF HRQOL}

Measures of HRQOL are classified as either disease targeted or generic. Disease-targeted measures are used for patients with a particular diagnosis, whereas generic measures can be used in any population. There are two major approaches to assessment of HRQOL: psychometric and decision theory.

The psychometric approach provides a profile of measures, each summarizing a different dimension of HRQOL. The bestknown example of the psychometric tradition is the Medical Outcomes Study 36-item Short Form (SF-36) (2), a generic measure of HRQOL.

The decision theory approach weights the different dimensions of HRQOL to provide a single expression of quality of life. Supporters of this approach argue that psychometric methods fail to consider that different health problems cause different levels of concern. A minor itch and coughing blood are both symptoms, but they are not equal in importance. Furthermore, a treatment may improve some aspects of quality of life while causing others to deteriorate. For example, a medication might reduce coughing, but increase skin problems or reduce energy. When components of outcome change in different directions, an overall subjective evaluation is required to integrate the components and offer a summary of whether the patient is better or worse off. The decision theory approach attempts to provide an overall measure of HRQOL that integrates subjective function states, preferences for these states, morbidity, and mortality.

Measures can also be distinguished by their possible uses. Most measures can be used to characterize populations and to study clinical changes. However, only generic decision theorybased measures can be used to evaluate cost-effectiveness.

\section{DISEASE-TARGETED METHODS OF HRQOL}

Commonly used measures of HRQOL in patients with lung diseases are described briefly below and summarized in Table 1.

\section{The Chronic Respiratory Questionnaire}

The Chronic Respiratory Questionnaire (CRQ) is a 20-item interviewer-administered instrument that evaluates four domains: dyspnea, fatigue, emotional function, and mastery. For the dyspnea measure, patients rate breathlessness on the five most important activities of daily living (ADLs) chosen from a standard list. Therefore, the measure of dyspnea is unique to each individual and cannot be compared among subjects. Changes on 
TABLE 1. DISEASE-TARGETED QUALITY-OF-LIFE MEASURES COMMONLY USED TO EVALUATE OUTCOMES IN ADULTS WITH CHRONIC LUNG DISEASES

\begin{tabular}{|c|c|c|}
\hline Measure & Type & Uses \\
\hline Chronic Respiratory Questionnaire (CRQ) & Profile & Descriptive studies, assess clinical change \\
\hline St. George's Respiratory Questionnaire (SGRQ) & Profile & Descriptive studies, assess clinical change \\
\hline $\begin{array}{l}\text { University of California, San Diego, Shortness } \\
\text { of Breath Questionnaire (SOBQ) }\end{array}$ & Profile/dyspnea-specific & Descriptive studies, assess clinical change \\
\hline
\end{tabular}

Data from Reference 1.

the questionnaire have been shown to correlate with changes in spirometric values, exercise performance, and subjective ratings of improvement by both the patients and physicians (3). The questionnaire is sensitive to a variety of interventions, including bronchodilator treatment (4-6). The original CRQ required a trained interviewer. More recently, a validated self-administered form has become available (7).

\section{St. George's Respiratory Questionnaire}

The St. George's Respiratory Questionnaire (SGRQ) is a selfadministered 50-item instrument with three separate scales (symptoms, activity, and impacts on daily life). A total score can also be calculated. The individual SGRQ questions are weighted differentially to produce an overall score. The questionnaire has been evaluated for reliability and validity in several chronic lung diseases of varying severity, particularly COPD and asthma (8). We offer more on the sensitivity of the SGRQ in a later section.

\section{DYSPNEA}

Despite the advantages of disease-specific and generic quality-oflife measures, pulmonologists have been concerned that these approaches may miss some of the most important patient outcomes. For example, several studies have observed low correlations between measures of generic quality of life and lung function. Dyspnea is the one common self-reported patient outcome that may have a profound effect on HRQOL (9). Several studies show that the correlation between generic quality of life and dyspnea is substantial. Schrier and colleagues found no correlation between lung function tests and scores on a generic profile measure known as the Sickness Impact Profile (SIP) (10). However, they did observe substantial correlations between symptoms of wheezing and dyspnea and SIP scores. Yet, the general measures miss many of the subtle characteristics or subtle aspects of the clinically important symptoms. These findings suggest that measures of shortness of breath or dyspnea may be of central importance for evaluating outcomes in emphysema.

We believe that HRQOL assessment in studies of patients with emphysema should be complemented by measures of shortness of breath. However, measurement of dyspnea presents several methodologic and technical challenges. A number of instruments are available to assess dyspnea, including structured interviews and self-report questionnaires that evaluate a patient's historical recall of breathlessness. These measures compare shortness of breath associated with daily activities or exercise to symptoms occurring at that specific time when the assessment is made (Table 2). A review of dyspnea measures by Eakin and colleagues offers more details about the measures and their properties (11).

The University of California, San Diego, Shortness of Breath Questionnaire (UCSD-SOBQ) exemplifies a validated dypsnea measure. The SOBQ is self-administered and asks subjects to rate their breathlessness for 21 various daily activities (plus 3 overall items) on a 6-point scale from none at all (0) to severe (4), to maximal or unable to do because of breathlessness (5) (12). For activities that they do not typically perform, respondents estimate their breathlessness for that activity. The 21 ADLs are grouped into four categories of ADLs: rest and light ADLs (factor 1), 8 questions; moderate ADLs (factor 2), 5 questions; walking (factor 3), 4 questions; and strenuous ADLs (factor 4), 4

TABLE 2. COMMONLY USED DYSPNEA MEASURES

\begin{tabular}{|c|c|c|}
\hline Measure & Description & Validity Evidence \\
\hline $\begin{array}{l}\text { British Medical Research Council } \\
\quad(\text { MRC) }\end{array}$ & $\begin{array}{l}\text { Five yes/no questions about shortness of breath. Requires recall. Higher } \\
\text { score indicates more shortness of breath. }\end{array}$ & $\begin{array}{l}r=-0.53 \text { with other dyspnea } \\
\text { measures, } r=-0.42 \text { with } \mathrm{FEV}_{1.0}\end{array}$ \\
\hline $\begin{array}{l}\text { American Thoracic Society Respiratory } \\
\text { Questionnaire }\end{array}$ & $\begin{array}{l}\text { Five yes/no items. Similar to MRC, but asks about magnitude of effort and } \\
\text { impairment. Requires recall. Higher score indicates more impairment. }\end{array}$ & $r=0.50$ with MRC questionnaire \\
\hline $\begin{array}{l}\text { Baseline and Transition Dyspnea } \\
\text { Indexes (BDI-TDI) (57) }\end{array}$ & $\begin{array}{l}\text { Single ratings in three categories. Ratings of transition require recall of } \\
\text { baseline dyspnea. Higher score indicates more dypsnea. }\end{array}$ & $\begin{array}{l}r=0.53 \text { with other dyspnea } \\
\text { indexes, } r=0.60 \text { with } \\
\text { six-minute-walk distance }\end{array}$ \\
\hline Modified Dyspnea Index (58) & $\begin{array}{l}\text { Ratings for impairment at work and impairment at home. Similar to BDI. } \\
\text { Requires recall. Higher score indicates more impairment. }\end{array}$ & $r=0.71$ with $\mathrm{FEV}_{1.0}$ \\
\hline Oxygen Cost Diagram (OCD) (59) & $\begin{array}{l}\text { Ratings of breathlessness with different activities on } 10-\mathrm{cm} \text { line associated } \\
\text { with activities of daily living. Requires recall. Higher score indicates more } \\
\text { breathlessness. }\end{array}$ & $\begin{array}{l}r=0.68 \text { with six-minute-walk } \\
\text { distance, } r=-053 \text { to }-0.79 \\
\text { with other dyspnea measures }\end{array}$ \\
\hline Visual Analogue Scale (VAS) (60) & $\begin{array}{l}\text { 10-cm line to rate perceived symptom associated with exercise or physical } \\
\text { stimulus. This measure does not require recall—ratings are taken during } \\
\text { activity. Higher score indicates greater severity of symptom. }\end{array}$ & $\begin{array}{l}r=-0.85 \text { with peak expiratory } \\
\text { flow rate }\end{array}$ \\
\hline Borg scale (61) & $\begin{array}{l}\text { Rating scale of } 0 \text { to } 10 \text { for rating intensity of breathlessness on 1-10 log } \\
\text { scale. This measure does not require recall—ratings are taken during } \\
\text { activity. Higher score indicates greater breathlessness. }\end{array}$ & $r$ with $\mathrm{FEV}_{1.0}=0.88$ \\
\hline $\begin{array}{l}\text { University of California, San Diego, } \\
\text { Shortness of Breath Questionnaire } \\
\text { (UCSD-SOBQ) (12) }\end{array}$ & $\begin{array}{l}\text { Self-ratings of breathlessness for } 21 \text { various daily activities (plus } 3 \text { overall } \\
\text { items) on a 6-point scale from none at all (0) to severe (4) to maximal or } \\
\text { unable to do because of breathlessness (5). }\end{array}$ & $\begin{array}{l}r=-0.40 \text { with } \mathrm{QWB},-0.68 \text { with } \\
\text { six-minute-walk distance, }-0.67 \\
\text { with } \mathrm{D} \mathrm{L}_{\mathrm{co}} \% \text { predicted }\end{array}$ \\
\hline
\end{tabular}

Data from Reference 1.

Note: More detailed descriptions of the measures and validity studies are summarized in Reference 11. 
questions. The score on each of the 24 items is summed to produce a total score (range of 0 to 120). To represent a range of disease-specific outcomes, the NETT selected the SGRQ and the UCSD-SOBQ.

\section{GENERIC METHODS OF HRQOL}

Generic HRQOL measures can evaluate outcomes for any population (as compared with disease-targeted measures that measure outcomes for people with a particular health condition). Some of the common generic approaches are summarized in Table 3. Readers interested in more detail should consult Shumaker and Berzon (13) or Walker and Rosser (14) and McDowell and Newell (15).

\section{SF-36}

Perhaps the most commonly used generic HRQOL measure in the world today is the Medical Outcomes Study SF-36. The SF-36 uses the psychometric or profile approach and grew out of work by the Rand Corporation and the Medical Outcomes Study (2). The SF-36 includes eight health concepts: physical functioning, role-physical, bodily pain, general health perceptions, vitality, social functioning, role-emotional, and mental health (16). The SF-36 is either administered by a trained interviewer or selfadministered. The SF-36 can be machine scored and has been evaluated in large-population studies. The reliability, validity, and sensitivity of the SF-36 are well documented (17-19). Despite its many advantages, the SF-36 also presents some disadvantages. For example, it does not have age-specific questions, and one cannot clearly determine whether it is equally appropriate at each level of the age continuum. The items for older retired individuals are the same as those for children (17).

Some approaches to the measurement of HRQOL combine measures of morbidity and mortality to express health outcomes in units analogous to years of life. The years-of-life measure can be adjusted for diminished quality of life associated with diseases or disability (20). We consider three utility-based approaches.

\section{Quality of Well-Being Scale}

The Quality of Well-Being scale (QWB) combines preferenceweighted values for symptoms and functioning. The preference weights were obtained by ratings of 856 people from the general population. These judges rated the desirability of health conditions to place each on the continuum between death $(0.00)$ and optimum health (1.00). Symptoms are assessed by questions that ask about the presence or absence of different symptom complexes. Functioning is assessed by a series of questions designed to record functional limitations over the previous 3 days, within three separate domains (mobility, physical activity, and social activity). The four domain scores are combined into a total score that provides a numerical point-in-time expression of well-being that ranges from zero (0) for death to one (1.0) for asymptomatic optimum functioning.

The QWB has been used in numerous clinical trials and studies to evaluate medical and surgical therapies in conditions such as COPD (21) and several other conditions, (35-39). Furthermore, the method has been used for health resource allocation modeling and has served as the basis for an innovative experiment on rationing of health care by the state of Oregon $(36,37)$. A self-administered form of the QWB (QWB-SA) is available and it now the most commonly used form of the QWB.

\section{EuroQol Group 5 Dimension}

The approach most commonly used in the European community is the EuroQol Group 5 Dimension (EQ-5D). This method has been advanced by a collaborative group from Western Europe known as the EuroQol group (44). The original version of the EuroQol had 14 health states in six different domains. In addition, respondents placed their health on a continuum ranging from death (0.0) to perfect health (1.0). The method was validated in postal surveys in England, Sweden, and the Netherlands. More recent versions of the EuroQol, known as the EQ-5D, are now in use in a substantial number of clinical and population studies $(40,41)$. Although the EQ-5D is easy to use and comprehensive, there have been some concerns about ceiling effects. Substantial numbers of people obtain the highest possible score.

\section{Health Utilities Index}

The Health Utilities Index (HUI) is a family of health status and preference-based HRQOL measures suitable for use in clinical and population studies $(42,43)$. Each member of the family includes a health status classification system, a preference-based multiattribute utility function, data collection questionnaires, and algorithms for deriving HUI variables from questionnaire responses. The most commonly used versions are the HUI Mark 2 (HUI2) and the HUI Mark 3 (HUI3). HUI3 consists of eight attributes: vision, hearing, speech, ambulation, dexterity, emotion, cognition, and pain (43). There are five to six levels per attribute. HUI3 focuses on capacity rather than performance. Multiplicative multiattribute utility functions based on community preferences have been estimated for HUI2 (45) and HUI3 (42). Evidence on responsiveness and construct validity is provided by Torrance and coworkers (45). Evidence of

TABLE 3. COMMONLY USED GENERIC MEASURES OF QUALITY OF LIFE

\begin{tabular}{|c|c|c|}
\hline Method & Description & Advantages \\
\hline Medical Outcomes Short Form 36 (SF-36) & $\begin{array}{l}\text { Includes eight health concepts: physical functioning, } \\
\text { role-physical, bodily pain, general health perceptions, } \\
\text { vitality, social functioning, role-emotional, and } \\
\text { mental health (16). }\end{array}$ & $\begin{array}{l}\text { The reliability and validity of the SF-36 are well } \\
\text { documented (17-19). }\end{array}$ \\
\hline EuroQol Group 5 Dimension (EQ-5D) & $\begin{array}{l}\text { Includes five dimensions, each with three levels; it has } \\
\text { been validated in postal surveys in England, Sweden, } \\
\text { and the Netherlands }\end{array}$ & $\begin{array}{l}\text { EQ-5D is now in use in a substantial number of clinical } \\
\text { and population studies }(40,41) \text {. }\end{array}$ \\
\hline $\begin{array}{l}\text { Health Utilities Index (HUI2). The HUI } \\
\text { is a family of health status and } \\
\text { preference-based HRQOL measures } \\
(42,43) \text {. }\end{array}$ & $\begin{array}{l}\text { Consists of seven dimensions of health status: sensation, } \\
\text { mobility, emotion, cognition, self-care, pain, and } \\
\text { fertility (43). There are five to six levels per dimension. }\end{array}$ & $\begin{array}{l}\text { Widely used in Canada and Europe. Excellent record of } \\
\text { reliability and validity. Well-grounded in economic } \\
\text { theory. }\end{array}$ \\
\hline $\begin{array}{l}\text { Self-administered Quality of Well-Being } \\
\text { scale (QWB-SA) }\end{array}$ & $\begin{array}{l}\text { Combines preference-weighted values for symptoms } \\
\text { and functioning. }\end{array}$ & $\begin{array}{l}\text { Has been used in numerous clinical trials and population } \\
\text { studies (21-35). }\end{array}$ \\
\hline Fryback Index (48) & Estimates QWB scores based on SF-36 responses. & $\begin{array}{l}\text { Can be used to estimate utility data for cost-effectiveness } \\
\text { analysis using existent SF-36 data. }\end{array}$ \\
\hline
\end{tabular}


construct validity in the 1990 Ontario Health Survey is provided in Grootendorst (46). HUI3 described the burden of morbidity for both stroke and arthritis. Problems were found in the attributes that had been expected to be affected.

\section{QUALITY-ADJUSTED YEARS OF LIFE}

The QWB, EQ-5D, and the HUI are important because they can be used to obtain quality-adjusted life-years (QALYs). QALYs combine measures of quality of life and years of life to adjust the years-of-life measure for the diminished quality of life associated with diseases or disabilities (20). Modern measures of health outcome consider future as well as current health status. Lung cancer, for example, may have very little impact on current functioning but may have a substantial impact on life expectancy and functioning in the future. Today, a person with a malignant tumor in a lung may be functioning very much like a person with a chest cold. However, the patients with cancer is more likely to remain dysfunctional or to die in the near future. Comprehensive expressions of health status need to incorporate estimates of future outcomes as well as measure current status (47). For example, surgical intervention for emphysema may have short-term consequences that will reduce HRQOL. However, both HRQOL and life expectancy gains may result from the surgery. QALY methods can express this comprehensive effect of the treatment.

Most of the methods for obtaining QALYs are similar (35). The most commonly used methods are the EQ-5D, the HUI, and the QWB. Methods for translating SF-36 scores into the QWB scores (so that the SF-36 scores can be used to calculate QALYs) have emerged (48). After considerable discussion, the NETT selected the QWB.

\section{INTEGRATING COST WITH OUTCOME DATA}

Although treatment programs provide health benefits, they also have costs. Not all health care interventions equally return benefit for the expended dollar. Resources are limited, and good policy requires that they be used wisely. Cost-effectiveness studies have gained in popularity because health care costs have grown so rapidly in recent years. Objective cost studies might guide policymakers toward an optimal and equitable distribution of scarce resources. Methodologies for estimating costs have now become standardized (49). From an administrative perspective, cost estimates include all treatment costs and any costs associated with treating side effects. Typically, economic discounting is applied to adjust for using current assets to achieve a future benefit. From a social perspective, costs are broader and may include indirect costs of family members missing work to provide care. Comparing treatment programs for populations with a given medical condition, cost-effectiveness is measured as the change in costs of care for the new intervention compared with the existing therapy or program, relative to the change in health measured in a standardized unit such as the QALY. The difference in costs over the difference in effectiveness is the incremental cost-effectiveness and is usually expressed as the cost/QALY. Because the objective of all programs is to produce QALYs, the cost-QALY ratio can be used to show the relative health benefits from investing in different programs (35). Several different governments have proposed allocating resources based on systematic data (37). For example, the Australian government now requires evidence of effectiveness, as do a variety of European governments. In Ontario, Canada, QALYs have been considered as a basis for formulary decisions (50). Similar proposals have been considered in the United Kingdom (51).

\section{HRQOL ASSESSMENT IN THE NETT}

The NETT was one of the first randomized clinical trials of emphysema treatment to prospectively integrate quality-of-life assessment. The NETT compared LVRS plus maximal medical therapy with medical therapy alone. Four quality-of-life measures were administered at baseline and again at 6, 12, 24, 36, 48, and 60 months after treatment assignment. The trial used two generic HRQOL measures (the QWB-SA and the SF-36) and two disease-targeted measures (the SGRQ and the UCSD-SOBQ).

\section{HRQOL at Baseline}

Pairwise correlations between HRQOL measures obtained at baseline (SOBQ total score, QWB-SA total score, SGRQ total score, SF-36 physical component score [PCS] and mental component score [MCS]) were all statistically significant and ranged from 0.31 to 0.70 except for the PCS with the MCS; the PCS and MCS scores were originally derived from factor analysis and are expected to be uncorrelated (52). On average, the NETT participants had lower scores on the QWB-SA compared with a comparable normative population. With the exception of the SF-36 scores for bodily pain and MCS, all other SF-36 measures show NETT participants to be well below the population norms. For the QWB-SA and the SF-36 subscales (other than the PCS and MCS), the normative sample was older adults selected from the general population in Beaver Dam, Wisconsin (mean age, $64.1 \mathrm{yr}$ ) (53). Because the Beaver Dam sample did not include PCS and MCS scores, SF-36 general population norms for the U.S. population in the age category of 55-64 years (54) were used to assess the PCS and MCS scores of the NETT participants. These summary measures suggest that the NETT participants were quite ill. All of the HRQOL measures were significantly associated with the number of hospital days in the 3 months before NETT enrollment (all $P$ values $<0.001)(52)$.

\section{HRQOL Changes after Rehabilitation}

The NETT evaluated HRQOL before and after comprehensive pulmonary rehabilitation. There were significant improvements on all HRQOL measures after rehabilitation. The correlations between the changes in HRQOL measures and the change in the six-minute-walk distance between baseline and the completion of rehabilitation were all modest, but statistically significant. This suggests that those who improved in exercise also improved on HRQOL measures (52). The pre- and postrehabilitation means and the effect sizes for change are shown in Table 4. Effect size is used to describe the magnitude of a treatment effect. The effect size is an important index because it is independent of the sample size and not entirely dependent on statistical significance. There

TABLE 4. PRE- AND POSTPULMONARY REHABILITATION QUALITY-OF-LIFE OUTCOMES*

\begin{tabular}{lcccc}
\hline Variable & Pre & Post & $P$ Value & Effect Size \\
\hline SF-36 Physical Health (PCS) & 28.3 & 29.7 & $<0.001$ & 0.19 \\
SF-36 Mental Health (MCS) & 53.2 & 55.3 & $<0.001$ & 0.21 \\
SGRQ & 56.5 & 53.1 & $<0.001$ & 0.35 \\
UCSD-SOBQ & 66.7 & 62.5 & $<0.001$ & 0.24 \\
QWB-SA & 0.537 & 0.571 & $<0.001$ & 0.29 \\
\hline
\end{tabular}

Definition of abbreviations: MCS = mental component score; PCS = physical component score; QWB-SA = self-administered Quality of Well-Being scale; SF-36 = Medical Outcomes Study Short Form 36; SGRQ = St. George's Respiratory Questionnaire; UCSD-SOBQ = University of California, San Diego, Shortness of Breath Questionnaire.

Data from Reference 52.

${ }^{*} \mathrm{n}=1,209-1,216$ pairs. 
are a variety of indexes of effect size, but most consider the difference between treatment and control means divided by the standard deviation of the pooled groups.

The effect sizes were in a comparable range for generic and disease-targeted measures. The NETT results are consistent with a variety of studies, summarized in a recent Cochrane review, that have documented HRQOL benefits resulting from pulmonary rehabilitation (55).

\section{HRQOL after Surgery}

In May 2001, recruitment into the NETT trial was halted for patients with an $\mathrm{FEV}_{1} \leqslant 20 \%$ predicted and either homogeneous emphysema on computed tomography scan or $\mathrm{DL}_{\mathrm{CO}} \leqslant$ $20 \%$ predicted. A total of 1,078 patients who did not have highrisk characteristics completed the trial (56). Patients randomly assigned to LVRS obtained lower (more favorable) scores on the UCSD-SOBQ and the total score on the SGRQ. For these measures, groups began to separate by the 6-month follow-up and the differences remained significant through 60 months. Similar trends were observed for the generic QWB-SA and the physical component of the SF-36.

Overall, the NETT trial suggests that LVRS leads to improvements in HRQOL for non-high-risk patients with emphysema. The benefits may be stronger for certain subgroups of patients. Patients randomly assigned to LVRS achieved better outcomes on the SGRQ, the UCSD-SOBQ, and the QWB-SA. These findings suggest that LVRS may result in enhancements in everyday functioning, particularly in activities associated with shortness of breath.

\section{Cost-effectiveness Analysis}

The outcomes on the QWB-SA were combined with mortality outcomes to express the benefits of LVRS in terms of QALYs. These measures are the central metric for cost-effectiveness analysis (see Ramsey and coworkers, pages 406-411, in this symposium [62]). The NETT suggested that, in comparison to maximal medical therapy, LVRS produces a QALY for about $\$ 190,000$, considering a 3-year time horizon. If the time horizon is expanded to 10 years, the cost-QALY was estimated to be $\$ 53,000$. The cost-QALY was even more attractive for some subgroups.

\section{CONCLUSIONS}

Quality-of-life measures evolve from two different measurement traditions: psychometric theory and decision theory. Psychometric methods, such as the SF-36, typically create a profile of outcomes, whereas decision theory methods attempt to portray an integrative summary judgment of health. Decision theory methods are better suited for cost-effectiveness studies.

A review of current outcomes research for emphysema shows that quality-of-life measures are now commonly used. There is substantial evidence for the validity of these measures for patients with chronic lung diseases. The NETT showed that, in comparison to maximal medical therapy alone, non-high-risk patients undergoing maximal medical therapy plus LVRS experience improved HRQOL. Data from the prerandomization phase of the NETT indicate that patients with emphysema who complete rehabilitation experience significant improvements on several indexes of life quality. The NETT also illustrated how quality-of-life data can be used to assess outcomes in major clinical trials and how they can be applied in cost-effectiveness analysis (see Ramsey and coworkers, pages 406-411, in this symposium [62]). Analyses from NETT suggest that the costeffectiveness of LVRS is justifiable in comparison to other medical and surgical treatments and can be as low as $\$ 21,000$ per QALY for patients with upper-lobe emphysema and low exercise capacity if a 10-year time horizon is used. We urge that quality-of-life measurement become a standard part of outcomes assessment in emphysema clinical research.

Conflict of Interest Statement: R.M.K. does not have a financial relationship with a commercial entity that has an interest in the subject of this manuscript. A.L.R. received $\$ 50,000$ from Boehringer Ingelheim as research grants for participating in a multicenter clinical trial.

\section{References}

1. Kaplan RM, Ries AL. Quality of life as an outcome measure in pulmonary diseases. J Cardiopulm Rehabil 2005;25:321-331.

2. Ware JE Jr, Gandek B. Overview of the SF-36 Health Survey and the International Quality of Life Assessment (IQOLA) project. J Clin Epidemiol 1998;51:903-912.

3. Guyatt GH, Berman LB, Townsend M, Pugsley SO, Chambers LW. A measure of quality of life for clinical trials in chronic lung disease. Thorax 1987;42:773-778.

4. Guyatt GH, Townsend M, Pugsley SO, Keller JL, Short HD, Taylor DW, Newhouse MT. Bronchodilators in chronic air-flow limitation. Effects on airway function, exercise capacity, and quality of life. $A m$ Rev Respir Dis 1987;135:1069-1074.

5. Guyatt GH, Townsend M, Keller JL, Singer J. Should study subjects see their previous responses: data from a randomized control trial. J Clin Epidemiol 1989;42:913-920.

6. Jaeschke R, Guyatt GH, Keller J, Singer J. Interpreting changes in quality-of-life score in $\mathrm{N}$ of 1 randomized trials. Control Clin Trials 1991;12(4, Suppl)226S-233S.

7. Tu SP, McDonell MB, Spertus JA, Steele BG, Fihn SD. A new selfadministered questionnaire to monitor health-related quality of life in patients with COPD. Ambulatory Care Quality Improvement Project (ACQUIP) Investigators. Chest 1997;112:614-622.

8. Jones PW, Quirk FH, Baveystock CM. The St. George's Respiratory Questionnaire. Respir Med 1991;85(Suppl B):25-31[Discussion, 33-27.]

9. Khanna D, Clements PJ, Furst DE, Chon Y, Elahoff R, Roth MD, Sterz MG, Chung J, FitzGerald JD, Seibold JR, et al. Correlation of the degree of dyspnea with health-related quality of life, functional abilities, and diffusing capacity for carbon monoxide in patients with systemic sclerosis and active alveolitis: results from the Scleroderma Lung Study. Arthritis Rheum 2005;52:592-600.

10. Schrier AC, Dekker FW, Kaptein AA, Dijkman JH. Quality of life in elderly patients with chronic nonspecific lung disease seen in family practice. Chest 1990;98:894-899.

11. Eakin EG, Kaplan RM, Ries AL. Measurement of dyspnoea in chronic obstructive pulmonary disease. Qual Life Res 1993;2:181-191.

12. Eakin EG, Resnikoff PM, Prewitt LM, Ries AL, Kaplan RM. Validation of a new dyspnea measure: the UCSD Shortness of Breath Questionnaire. University of California, San Diego. Chest 1998;113:619-624.

13. Shumaker SA, Berzon R. The international assessment of health-related quality of life: theory, translation, measurement and analysis. New York: Oxford; 1995.

14. Walker SR, Rosser R. Quality of life assessment: key issues in the 1990s. Dordrecht and Boston: Kluwer Academic Publishers; 1993.

15. McDowell I, Newell C. Measuring health: a guide to rating scales and questionnaires, 2nd ed. New York: Oxford University Press; 1996.

16. Kosinski M, Keller SD, Hatoum HT, Kong SX, Ware JE Jr. The SF-36 Health Survey as a generic outcome measure in clinical trials of patients with osteoarthritis and rheumatoid arthritis: tests of data quality, scaling assumptions and score reliability. Med Care 1999;37(5, Suppl):MS10-MS22.

17. Stewart AL, Ware JE. Measuring functioning and well-being: the Medical Outcomes Study approach. Durham, NC: Duke University Press; 1992.

18. Scott-Lennox JA, Wu AW, Boyer JG, Ware JE Jr. Reliability and validity of French, German, Italian, Dutch, and UK English translations of the Medical Outcomes Study HIV Health Survey. Med Care 1999;37:908-925.

19. Keller SD, Ware JE Jr, Hatoum HT, Kong SX. The SF-36 ArthritisSpecific Health Index (ASHI): II. Tests of validity in four clinical trials. Med Care 1999;37(5, Suppl):MS51-MS60.

20. Kaplan RM, Feeny D, Revicki DA. Methods for assessing relative importance in preference based outcome measures. In: Joyce CRB, O'Boyle CA, McGee H, editors. Individual quality of life: approaches 
to conceptualisation and assessment. Amsterdam, The Netherlands: Harwood; 1999. pp. 135-149.

21. Kaplan RM, Atkins CJ, Timms R. Validity of a quality of well-being scale as an outcome measure in chronic obstructive pulmonary disease. J Chronic Dis 1984;37:85-95.

22. Kaplan RM, Patterson TL, Kerner DN, Atkinson JH, Heaton RK, Grant I. The Quality of Well-Being scale in asymptomatic HIVinfected patients. HNRC Group. HIV Neural Behavioral Research Center. Qual Life Res 1997;6:507-514.

23. Kaplan RM, Anderson JP, Patterson TL, McCutchan JA, Weinrich JD, Heaton RK, Atkinson JH, Thal L, Chandler J, Grant I. Validity of the Quality of Well-Being scale for persons with human immunodeficiency virus infection. HNRC Group. HIV Neurobehavioral Research Center. Psychosom Med 1995;57:138-147.

24. Orenstein DM, Pattishall EN, Nixon PA, Ross EA, Kaplan RM. Quality of well-being before and after antibiotic treatment of pulmonary exacerbation in patients with cystic fibrosis. Chest 1990;98:1081-1084.

25. Orenstein DM, Kaplan RM. Measuring the quality of well-being in cystic fibrosis and lung transplantation: the importance of the area under the curve. Chest 1991;100:1016-1018.

26. Kaplan RM, Hartwell SL, Wilson DK, Wallace JP. Effects of diet and exercise interventions on control and quality of life in non-insulindependent diabetes mellitus. J Gen Intern Med 1987;2:220-228.

27. Ganiats TG, Palinkas LA, Kaplan RM. Comparison of Quality of WellBeing scale and Functional Status Index in patients with atrial fibrillation. Med Care 1992;30:958-964.

28. Squier HC, Ries AL, Kaplan RM, Prewitt LM, Smith CM, Kriett JM, Jamieson SW. Quality of well-being predicts survival in lung transplantation candidates. Am J Respir Crit Care Med 1995;152:20322036.

29. Kaplan RM, Schmidt SM, Cronan TA. Quality of well being in patients with fibromyalgia. $J$ Rheumatol 2000;27:785-789.

30. Kaplan RM, Alcaraz JE, Anderson JP, Weisman M. Quality-adjusted life years lost to arthritis: effects of gender, race, and social class. Arthritis Care Res 1996;9:473-482.

31. Rocco MV, Gassman JJ, Wang SR, Kaplan RM. Cross-sectional study of quality of life and symptoms in chronic renal disease patients: the Modification of Diet in Renal Disease Study. Am J Kidney Dis 1997; 29:888-896.

32. Kaplan RM. Quality of life assessment for cost/utility studies in cancer. Cancer Treat Rev 1993;19(Suppl A):85-96.

33. Pyne JM, Patterson TL, Kaplan RM, Ho S, Gillin JC, Golshan S, Grant I. Preliminary longitudinal assessment of quality of life in patients with major depression. Psychopharmacol Bull 1997;33:23-29.

34. Pyne JM, Patterson TL, Kaplan RM, Gillin JC, Koch WL, Grant I. Assessment of the quality of life of patients with major depression. Psychiatr Serv 1997;48:224-230.

35. Kaplan RM, Ganiats TG, Sieber WJ, Anderson JP. The Quality of WellBeing scale: critical similarities and differences with SF-36. Int J Qual Health Care 1998;10:509-520.

36. Kaplan RM. Allocating health resources in California: learning from the Oregon experiment. California policy seminar. Berkeley, CA: California Policy Seminar; 1993.

37. Kaplan RM. Value judgment in the Oregon Medicaid experiment. Med Care 1994:32:975-988.

38. Bombardier C, Ware J, Russell IJ, Larson M, Chalmers A, Read JL. Auranofin therapy and quality of life in patients with rheumatoid arthritis: results of a multicenter trial. Am J Med 1986;81:565-578.

39. Kaplan RM, Sieber WJ, Ganiats TG. The Quality of Well-being scale: comparison of the interviewer-administered version with a self-administered questionnaire. Psychol Health 1997;12:783-791.

40. Hurst NP, Kind P, Ruta D, Hunter M, Stubbings A. Measuring healthrelated quality of life in rheumatoid arthritis: validity, responsiveness and reliability of EuroQol (EQ-5D). Br J Rheumatol 1997;36:551-559.
41. Gudex C, Dolan P, Kind P, Williams A. Health state valuations from the general public using the visual analogue scale. Qual Life Res 1996; 5:521-531.

42. Feeny D, Furlong W, Mulhern RK, Barr RD, Hudson M. A framework for assessing health-related quality of life among children with cancer. Int J Cancer Suppl 1999;12:2-9.

43. Feeny D, Furlong W, Boyle M, Torrance GW. Multi-attribute health status classification systems: Health Utilities Index. Pharmacoeconomics 1995;7:490-502.

44. Kind P. The performance characteristics of EQ-5D, a measure of health related quality of life for use in technology assessment [abstract]. Proceedings of the 13th Annual Meeting of the International Society of Technology Assessment in Health Care; 1997.

45. Torrance GW, Furlong W, Feeny D, Boyle M. Multi-attribute preference functions: Health Utilities Index. Pharmacoeconomics 1995;7:503-520.

46. Grootendorst P, Feeny D, Furlong W. Health Utilities Index Mark 3: evidence of construct validity for stroke and arthritis in a population health survey. Med Care 2000;38:290-299.

47. Kaplan RM. The Ziggy theorem: toward an outcomes-focused health psychology. Health Psychol 1994;13:451-460.

48. Fryback DG, Lawrence WF, Martin PA, Klein R, Klein BEK. Predicting quality of well-being scores from the SF-36: results from the Beaver Dam Health Outcomes Study. Med Decis Making 1997;17:1-9.

49. Gold MR. Cost-effectiveness in health and medicine. New York: Oxford University Press; 1996.

50. Detsky AS. Economics and cost-effectiveness in evaluating the value of cardiovascular therapies: terminology I would like to see disappear. Am Heart J 1999;137:S51-S52.

51. Williams A. Cochrane Lecture. All cost effective treatments should be free, or, how Archie Cochrane changed my life! J Epidemiol Community Health 1997;51:116-120.

52. Kaplan RM, Ries AL, Reilly J, Mohsenifar Z. Measurement of healthrelated quality of life in the National Emphysema Treatment Trial. Chest 2004;126:781-789.

53. Fryback DG, Dasbach EJ, Klein R, Klein BE, Dorn N, Peterson K, Martin PA. The Beaver Dam Health Outcomes Study: initial catalog of health-state quality factors. Med Decis Making 1993;13:89-102.

54. Ware JE. The SF-36 Health Survey. In: Spilker B, editor. Quality of life and pharmacoeconomics, 2nd ed. Philadelphia: Lippincott-Raven; 1996. pp. 337-345.

55. Lacasse Y, Goldstein R, Lasserson TJ, Martin S. Pulmonary rehabilitation for chronic obstructive pulmonary disease. Cochrane Database Syst Rev 2006;4:CD003793.

56. National Emphysema Treatment Trial Research Group. Patients at high risk of death after lung-volume-reduction surgery. N Engl J Med 2001; 345:1075-1083

57. Mahler DA, Weinberg DH, Wells CK, Feinstein AR. The measurement of dyspnea: contents, interobserver agreement, and physiologic correlates of two new clinical indexes. Chest 1984;85:751-758.

58. Stoller JK, Ferranti R, Feinstein AR. Further specification and evaluation of a new clinical index for dyspnea. Am Rev Respir Dis 1986; 134:1129-1134.

59. McGavin CR, Artvinli M, Nace H, McHardy GJ. Dyspnoea, disability and distance walked: comparison of estimates of exercise performance in respiratory disease. Int J Rehabil Res 1980;3:235-236.

60. Aitken RC. Measurement of feelings using visual analogue scales. Proc $R$ Soc Med 1969;62:989-993.

61. Borg G. Psychophysical scaling with applications in physical work and the perception of exertion. Scand J Work Environ Health 1990;16:55-58.

62. Ramsey SD, Sullivan SD, Kaplan RM. Cost effectiveness of lung volume reduction surgery. Proc Am Thorac Soc 2008;5:406-411. 